\title{
Uso de índices de reflectância das folhas para avaliar o nível de nitrogênio em grama-bermuda
}

\author{
Leaves reflectance index of the bermuda grass to evaluate the nutritional status in nitrogen
}

\author{
Claudinei Paulo de Lima' ${ }^{I}$ Clarice Backes ${ }^{I I}$ Dirceu Maximino Fernandes III

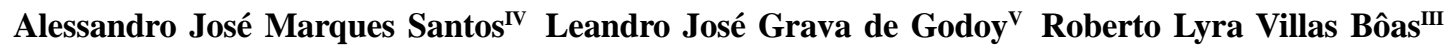

\section{RESUMO}

A reflectância da folha em determinados comprimentos de onda pode ser uma alternativa para estimar a concentração de nitrogênio $(N)$ na planta, devido à relação entre o teor de clorofila e de $N$ no tecido foliar. Este trabalho teve por objetivo avaliar índices da cor verde em grama-bermuda para predizer o nível de $\mathrm{N}$ na planta. O experimento foi conduzido em área comercial de produção de grama-bermuda, localizada na cidade de Capela do Alto/SP. O delineamento experimental utilizado foi de blocos ao acaso, com cinco tratamentos (0, 150,

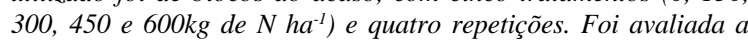
reflectância das folhas pelo uso de medidor de cor de grama, clorofilômetro, e por meio de análise da imagem digital. $O$ matiz $(H) e$ índice de cor verde escuro (ICVE), calculados com base nos índices de reflectância da imagem digital, o ICVE, obtido com medidor de cor de grama, e a intensidade de coloração verde (ICV), obtida com o clorofilômetro, apresentaram forte correlação positiva com a concentração de $N$ e a taxa de cobertura do solo (TCS) da grama-bermuda, podendo ser utilizados como índices auxiliares na recomendação de adubação nitrogenada para a cultura. Os valores obtidos que podem servir como primeiros índices para avaliação do estado nutricional em $N$ na grama-bermuda Celebration são: $H$ de 88 a $109^{\circ}$ e ICVE de 0,54 a 0,66 (imagem digital); $H$ de 67 a $76^{\circ}$ e ICVE de 0,41 a 0,44 (medidor de cor da grama TCM 500); e ICV de 374 a 471 (clorofilômetro CM 1000).

Palavras-chave: Cynodon dactylon (Pers) L, imagem digital, espectro, manejo nutricional.

\section{ABSTRACT}

Leaves reflectance in a certain wavelength can be an alternative to estimate the $N$ concentration in the plant

\begin{abstract}
because of the relationship between the chlorophyll content and $N$ in the leaf tissue. This research aimed to evaluate the index of green color of Bermuda grass to predict the nutritional status in $N$. The experiment was installed and conducted in an area of grass commercial production, located in "Capela do Alto / SP". The experimental design was randomized blocks, with five treatments: 0, 150, 300, 450 and $600 \mathrm{~kg} \mathrm{ha}^{-1}$ and four replications. It was evaluated the leaves reflectance by using the grass color meter, chlorophyll meter and by the digital image analysis. The hue $(H)$ and dark green color index (DGCI), calculated based on rates of reflectance of the digital image, the DGCI, obtained by grass color meter and intensity of green color obtained with chlorophyll meter presented strong positive correlation with $N$ concentration and the soil cover rate of Bermuda grass which can be used as auxiliary index to assist in the recommendation of nitrogen fertilization. The values that can serve as the primary index for assessing the nutritional status of $N$ in Celebration Bermuda grass are: $H 88$ to $109^{\circ}$ and DGCI 0.54 to 0,66 (digital image); $H 67$ to $76^{\circ}$ and DGCI 0.41 to 0.44 (TCM 500 color grass meter) and GCI 374 to 471 (CM 1000 chlorophyll metter).
\end{abstract}

Key words: Cynodon dactylon (Pers) L, digital image, spectrum, nutritional management.

\section{INTRODUÇÃO}

O N é o nutriente com maior influência em características de gramas, como coloração, crescimento e densidade da parte aérea, reserva de carboidratos, tolerância a baixas temperaturas, resistência à seca,

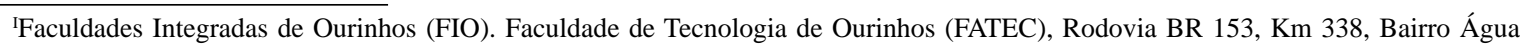
do Cateto, CP 105, 19909-100, Ourinhos, SP, Brasil. E-mail: neiagro@yahoo.com.br. Autor para correspondência.

"Iniversidade Estadual de Goiás (UEG), UnU de São Luis de Montes Belos, São Luis de Montes Belos, GO, Brasil.

IIIFaculdade de Ciências Agronômicas, Universidade Estadual Paulista (UNESP), Campus de Botucatu, Botucatu, SP, Brasil.

${ }^{\mathrm{IV}} \mathrm{UEG}$, UnU de Santa Helena de Goiás, Santa Helena de Goiás, GO, Brasil.

vUNESP, Campus Experimental de Registro, Registro, SP, Brasil.
} 
tolerância à compactação e ao pisoteio, acúmulo de material orgânico entre o solo e a parte aérea da grama (colchão) e potencial de recuperação (CARROW et al., 2001). No entanto, a quantidade de $\mathrm{N}$ disponível no solo é insuficiente para atender a alta exigência do gramado e, portanto, aplicações regulares de fertilizantes nitrogenados são necessárias para aumentar o crescimento das gramas (BOWMAN et al., 2002; EASTON \& PETROVIC, 2004).

Na falta de um índice do $\mathrm{N}$ disponível no solo para tomada de decisão da dose do adubo nitrogenado aplicado durante o ciclo da cultura da grama, um dos métodos utilizados é avaliar o comportamento da planta. A utilização do índice de cor verde da folha constitui-se em alternativa para estimar o nível de $\mathrm{N}$ na planta, devido à relação entre o teor de clorofila e de N (BACKES et al., 2010). Partindo do princípio de que a deficiência de $\mathrm{N}$ leva à redução na intensidade da coloração verde das folhas, estas medidas podem ser utilizadas para monitorar o teor de $\mathrm{N}$ de gramados.

Atualmente, com o avanço da tecnologia, aparelhos como o clorofilômetro CM 1000 (FieldScout Chlorophyll Meter - Spectrum ${ }^{\circledR}$ Technologies, Inc.) e o medidor de cor de grama (Turf Color Meter TCM 500 - Spectrum ${ }^{\circledR}$ Technologies, Inc.) foram colocados no mercado para a utilização em gramados. O clorofilômetro CM 1000 é um aparelho portátil, que mede a refletância das folhas nos comprimentos de onda do vermelho e do infravermelho, com área de leitura de até $277 \mathrm{~cm}^{2}$, permitindo avaliar muitas superfícies de folhas (MANGIAFICO \& GUILLARD, 2005). O medidor de cor da grama TCM 500 também fornece medida quantitativa das propriedades de cor de gramas, medindo o reflexo da luz para a grama nos espectros do vermelho, verde e azul.

A manipulação das imagens digitais, por meio de programas editores de imagem, fornece índices que expressam a cor verde da planta, correlacionandose positivamente com a concentração de $\mathrm{N}$ na folha (BACKES et al., 2010).

Objetivou-se, com este trabalho, avaliar índices de reflectância em grama-bermuda, obtidos pela análise da imagem digital e pela utilização do medidor de cor da grama TCM 500 e do clorofilômetro CM 1000 , para predizer o nível de $\mathrm{N}$ na planta e auxiliar na recomendação de adubação nitrogenada.

\section{MATERIAL E MÉTODOS}

O experimento foi realizado em propriedade comercial de produção de tapetes de grama-bermuda [Cynodon dactylon (Pers) L.], cultivar 'Celebration', localizada na cidade de Capela do Alto - SP. A gramabermuda tem hábito de crescimento rizomatoso e estolonífero e, portanto, pode ser colhida em área total, visto que, após a colheita, ficam rizomas subsuperficiais capazes de rebrotar para cobrir novamente o solo. A área vinha sendo utilizada para a produção comercial de grama, colhida mecanicamente em tapetes, há cerca de 4 anos, e o início do experimento ocorreu em uma área onde os tapetes haviam sido colhidos há 10 dias.

O solo utilizado é classificado como Latossolo Vermelho distrófico, de textura média (EMBRAPA, 2006) e, de acordo com o resultado da análise, na camada de $0-0,1 \mathrm{~m}$, apresentava os seguintes atributos químicos antes da instalação do experimento: $\mathrm{pH}\left(\mathrm{CaCl}_{2}\right)$ de 4,8; $18 \mathrm{~g} \mathrm{dm}^{-3}$ de matéria orgânica; $26 \mathrm{mg}$ $\mathrm{dm}^{-3}$ de P (resina); 37; 1,6; 16; 8 e $63 \mathrm{mmol}_{\mathrm{c}} \mathrm{dm}^{-3} \mathrm{de}$ $(\mathrm{H}+\mathrm{Al}), \mathrm{K}^{+}, \mathrm{Ca}^{2+}, \mathrm{Mg}^{2+}$ e CTC, respectivamente, e saturação por bases de $41 \%$. A calagem foi realizada em setembro de 2007, adicionando-se $0,70 \mathrm{t} \mathrm{ha}^{-1}$ de calcário dolomítico (PRNT = 91\%) para elevar o valor de $\mathrm{V}$ para $60 \%$ na camada de $0-0,1 \mathrm{~m}$. Aos trinta dias após a calagem, foi realizada a adubação fosfatada, adicionando-se $80 \mathrm{~kg} \mathrm{ha}^{-1}$ de $\mathrm{P}_{2} \mathrm{O}_{5}$, tendo como fonte $\mathrm{o}$ superfosfato triplo.

O delineamento experimental utilizado foi em blocos casualizados, com cinco tratamentos e quatro repetições. As parcelas experimentais constavam de $2,5 \times 5,0 m$ com $0,5 \mathrm{~m}$ de bordadura. Os tratamentos foram constituídos de cinco doses de N (0, 150, 300, 450 e $600 \mathrm{~kg} \mathrm{ha}^{-1}$ de $\mathrm{N}$ ) parceladas em três aplicações e acumulativas durante o ciclo da cultura. Aos 40 dias após a colheita do tapete anterior (DAC), o total aplicado foi de 0, 50, 100, 150 e $200 \mathrm{~kg} \mathrm{ha}^{-1}$ de N, aos 89 DAC: 0, 100, 200, 300 e 400 $\mathrm{kg} \mathrm{ha}^{-1}$ de $\mathrm{Ne}$, aos 124DAC, foi aplicado o restante do $\mathrm{N}$ para completar as doses totais de $0,150,300,450$ e $600 \mathrm{~kg} \mathrm{ha}^{-1}$ de N. A fonte de N utilizada foi a ureia (44\% de $\mathrm{N}$ ), aplicada manualmente na superfície do solo, sendo a área irrigada após a aplicação com uma lâmina de aproximadamente 20mm. A adubação potássica na dose de $200 \mathrm{~kg} \mathrm{ha}^{-1}$ de $\mathrm{K}_{2} \mathrm{O}$, também foi parcelada em três vezes na mesma época da adubação nitrogenada.

A concentração de $\mathrm{N}$ na lâmina foliar, a taxa de cobertura do solo pela grama (TCS) e os índices de reflectância da grama foram determinados aos 89 (novembro), 124 (dezembro) e 161 (fevereiro) DAC. A determinação da concentração de $\mathrm{N}$ foi realizada nas lâminas foliares de acordo com o método descrito por MALAVOLTA et al. (1997).

As imagens digitais foram obtidas com câmera digital Sony ${ }^{\circledR}$ DSC-W30 6.0 mega pixels, fixada na extremidade de estrutura na forma de " $L$ " invertido para que as imagens fossem obtidas paralelamente à 
superfície do gramado, em mesma altura $(1,6 \mathrm{~m})$. As imagens foram analisadas através do programa Corel Photo Paint ${ }^{\circledR}$ v. 10.410, (Corel Corporation, 2000), que permite contar o número de pontos (pixels) de determinada cor (e suas tonalidades) existente na imagem. Selecionando-se o número de pixels verdes e palha na imagem, foi possível determinar a porcentagem do solo coberto pela grama (TCS), conforme metodologia citada por GODOY (2005).

Os índices de cor verde da imagem digital também foram obtidos através do programa Corel Photo Paint $^{\circledR}$ v. 10.410. Foram anotados os valores médios dos componentes vermelho, verde e azul (RGB) da imagem analisada, fornecidos pelo comando "histograma”, do menu "imagem", após selecionar apenas o canal verde. Os componentes RGB são as quantidades de luz vermelha, verde e azul transmitidas pela imagem, sendo medidas em valores de 0 a 255 e são combinados em intensidades para produzir todas as outras cores.

Os resultados em RGB foram compilados em planilha do MS Excel ${ }^{\circledR}$ e convertidos para valores HSB (Hue - matiz, Saturation - saturação e Brigthness brilho), de acordo com KARCHER \& RICHARDSON (2003). O matiz descreve o pigmento de uma cor e é medido em graus de 0 a 360 (0 grau - vermelho; 60 graus - amarelo; 120 graus - verde; 180 graus - ciano; 240 graus - azul e 300 graus - magenta). A saturação descreve a vivacidade ou o esmaecimento de uma cor e é medida em porcentagem de 0 a 100 (quanto maior a porcentagem maior a vivacidade da cor). O brilho descreve a quantidade de branco que uma cor contém e é medido em porcentagem também de 0 a 100 (quanto maior a porcentagem, maior o brilho da cor).

O medidor de cor da grama TCM 500 mede a reflectância da luz pela grama no espectro vermelho, verde e azul, numa área circular de $44,2 \mathrm{~cm}^{2}$. O aparelho foi colocado em contato com a grama e pressionado para que não houvesse a penetração de luz solar. Com este aparelho, também foram obtidos os valores dos componentes RGB, sendo apresentados como um índice de 0 a 99 (obtidos pelo quociente entre o valor do componente vermelho, verde ou azul pelo fator 2,576). Com TCM 500, foram realizadas cinco leituras por parcela e, do mesmo modo que para a imagem digital, os resultados em RGB foram compilados em planilha do MS Excel ${ }^{\circledR}$ e convertidos para valores HSB. Os índices de reflectância da grama obtidos pela imagem digital e com a utilização do medidor TCM 500 foram: o componente verde $(\mathrm{G})$, o matiz da cor verde $(\mathrm{H})$ e o índice de cor verde escuro (ICVE). O ICVE, que varia de $0-1$, foi calculado utilizando-se os valores de HSB obtidos, de acordo com KARCHER \& RICHARDSON (2003).
Com o clorofilômetro CM 1000, foram realizadas cinco leituras em cada parcela, obtidas paralelamente à superfície do gramado, em mesma altura $(1,0 \mathrm{~m})$, correspondendo à área de leitura de $78,5 \mathrm{~cm}^{2}$, obtendo-se a intensidade de cor verde (ICV).

Os resultados foram submetidos à análise estatística, utilizando-se o software Sisvar versão 4.2 (FERREIRA, 2000). As correlações lineares foram obtidas pelo método de Pearson, utilizando-se o SigmaEstat versão 3.1 (Systat Software Inc., 2004).

\section{RESULTADOS E DISCUSSÃO}

Nas três épocas avaliadas, apenas o G obtido por imagem digital não foi influenciado pela dose de $\mathrm{N}$. Isso acontece porque não foram considerados os outros componentes da imagem (vermelho e azul), como citado por KARCHER \& RICHARDSON (2003). BACKES et al. (2010) observaram que o componente G da imagem digital foi influenciado pela dose de lodo de esgoto apenas aos 45 dias após a aplicação na grama esmeralda, não sendo influenciado nas demais épocas avaliadas (106 e 165 dias). Embora pareça ser intuitiva a utilização somente da quantidade de luz verde, não é eficiente para quantificar a cor verde da imagem. No sistema RGB, cada tom de cor é definido pelos três canais (vermelho, verde e azul), que variam como índices inteiros entre 0 e 255, permitindo uma combinação de 2563 (=16.777.216) tonalidades em cada pixel (GODINHO et al., 2008).

O H da cor verde da imagem da grama e ICVE, ambos calculados a partir da intensidade de luz vermelha, verde e azul, foram influenciados significativamente pela dose de N (Figura 1A e 1B). Nas três épocas avaliadas, os valores de $\mathrm{H}$ ajustaram-se melhor ao modelo quadrático, sendo atingido o ponto de inflexão com as doses de $\mathrm{N}$ de 150, 270 e $441 \mathrm{~kg} \mathrm{ha}^{-1}$, respectivamente, aos 89, 124 e 161 DAC. Os valores máximos obtidos com essas doses foram de 106, 109 e $88^{\circ}$. Segundo CARROW et al. (2001), quando as doses de N são muito altas, pode não haver resposta ou haver redução na cor verde da grama, devido à taxa de crescimento muito alta, provocando redução da concentração de clorofila, por efeito de diluição e, também, pelo sombreamento causado pelas folhas maiores.

O tratamento que não recebeu adubação nitrogenada apresentou valores de $\mathrm{H}$ de $79^{\circ}$, aos 89DAC, $75^{\circ}$, aos 124DAC, e $68^{\circ}$, aos 161DAC. O valor de $68^{\circ}$ está próximo da cor amarela $\left(60^{\circ}\right)$, caracterizando a clorose das folhas, sintoma típico da deficiência de $\mathrm{N}$, causado pela redução da concentração de clorofila. Segundo CHRISTIANS (2001), a cor verde das folhas não é importante no sistema de produção de grama, a não 

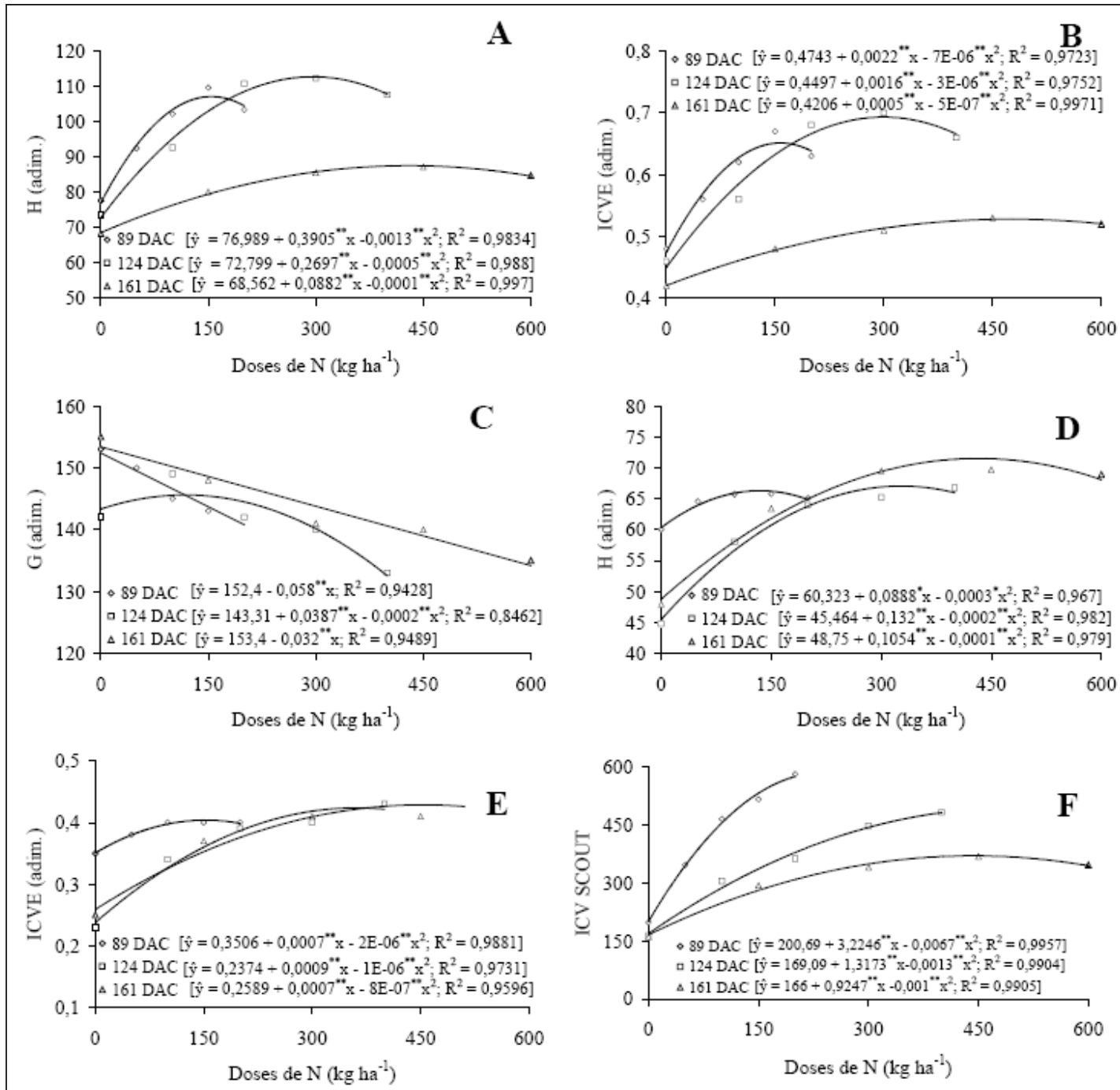

Figura 1- A - Matiz da cor verde (H) obtido através da análise da imagem digital; B - índice de cor verde escuro (ICVE) obtido através da análise da imagem digital; C - Componente de cor verde (G) obtido pelo do medidor TCM 500; D - Matiz da cor verde (H) obtido pelo medidor TCM 500; E - índice de cor verde escuro (ICVE) obtido pelo medidor TCM 500; F - intensidade de cor verde (ICV SCOUT) obtido com o clorofilômetro CM 1000, em função das doses de N, aos 89, 124 e 161 dias após o corte do tapete anterior (DAC).

ser alguns dias antes da colheita para a comercialização. No entanto, a manutenção da cor verde mais intensa representa concentrações maiores de clorofila, que favorecem a taxa fotossintética e, consequentemente, a produção de carboidratos e enraizamento mais rápido dos tapetes após o transplantio.

O ICVE também se ajustou de forma quadrática às doses de $\mathrm{N}$. De acordo com as equações, os máximos índices $(0,64,0,66$ e 0,54) foram obtidos com as doses de 157, 267 e 500 $\mathrm{kg} \mathrm{ha}^{-1}$ de N, aos 89, 124 e 161DAC, respectivamente, e os valores nas parcelas sem $\mathrm{N}$ variaram de 0,42 a 0,47. BACKES et al. (2010) verificaram, para a grama esmeralda adubada com lodo de esgoto, valores inferiores do ICVE obtidos no presente experimento, variando de 0,39, na ausência de aplicação do resíduo, provavelmente deficiente em $\mathrm{N}$, a 0,55 , no tratamento que recebeu a dose de $40 \mathrm{Mg}$ ha ${ }^{-1}$ de lodo, equivalente a $400 \mathrm{~kg} \mathrm{ha}^{-1}$ de N. Já KARCHER \& RICHARDSON (2003), ao trabalharem com a grama creeping bentgrass (Agrostis palustris L.), encontraram valores menores ainda que variaram de 0,37 a 0,50 , com os extremos para a condição de omissão da adubação nitrogenada e para a maior dose do nutriente $\left(600 \mathrm{~kg} \mathrm{ha}^{-1}\right)$, respectivamente. Assim, para 
cada espécie de grama, deverão ser estabelecidos os ICVEs de referência para auxiliar no manejo da adubação nitrogenada.

Quando se utilizou o medidor da cor da grama TCM 500 para a obtenção dos valores RGB, os índices $\mathrm{G}, \mathrm{H}$ e ICVE foram influenciados pelas doses de $\mathrm{N}$ nas três épocas analisadas (Figura 1C, 1D e 1E). O G (Figura 1C) diminuiu com o aumento da dose de N. Quanto menor o valor de G, mais intensa a cor verde, por isso há uma redução do seu valor com o aumento da dose de N. Mesmo não sendo considerados os demais componentes de cor (vermelho e azul), o componente verde permitiu o ajuste à dose de $\mathrm{N}$ em todas as épocas avaliadas, contrariamente do que aconteceu quando se utilizou a imagem digital. Neste caso, este ajuste pode ter ocorrido porque os valores de RGB foram obtidos numa câmara escura, que compõe o aparelho, não sofrendo influência da radiação solar, diferente da obtenção da imagem digital em plena luz solar, que varia com as épocas do ano.

Os índices calculados $\mathrm{H}$ e ICVE foram influenciados significativamente pela dose de $\mathrm{N}$; os resultados ajustaram-se ao modelo quadrático. Para o $\mathrm{H}$ (Figura 1D), as doses de 148, 330 e $527 \mathrm{~kg} \mathrm{ha}^{-1}$ proporcionaram os valores máximos $\left(67,67\right.$ e $\left.76^{\circ}\right)$, aos 89, 124 e 161DAC, respectivamente. De acordo com as equações ajustadas, as doses de 175, 450 e 437,5kg ha-1 de $\mathrm{N}$ proporcionaram os valores máximos de ICVE $(0,41$; 0,44; e 0,41), aos 89, 124 e 161DAC, respectivamente (Figura 1E). Os índices He ICVE obtidos com o medidor TCM 500 foram menores que os obtidos com a imagem digital, ficando clara a influência da radiação solar nos componentes RGB.

A ICV, medida pelo clorofilômetro CM 1000, também foi influenciada pela dose de $\mathrm{N}$ nas três épocas de avaliação. Aos 89 e 124DAC, a partir dos modelos quadráticos ajustados para a ICV em função da dose de $\mathrm{N}$, os valores máximos de intensidade de cor corresponderam a doses de $\mathrm{N}$ superiores às avaliadas (Figura 1F). Pode-se considerar que a ICV aumentou com a dose de $\mathrm{N}$ até 200 e 400kg ha-1 , aos 89 e 124DAC, respectivamente. CARROW et al. (2001) relatam que, quando a dose de $\mathrm{N}$ é aumentada a partir da condição de deficiência de $\mathrm{N}$, há um incremento no conteúdo de clorofila, proporcionando resposta linear na coloração verde da grama. Aos 161DAC, a dose de 462 $\mathrm{kg} \mathrm{ha}^{-1}$ proporcionou máxima ICV de 374.

Assim como aconteceu para os índices de cor verde analisados por imagem digital e pelo medidor de cor TCM 500, a intensidade de cor verde obtida pelo CM 1000 diminuiu ao longo do ciclo de cultivo. A diminuição dos índices de cor verde das folhas é explicada pela tendência de diminuição da concentração de $\mathrm{N}$ na folha ao longo do ciclo, resultante de efeito diluição, ou seja, com o aumento da massa da planta, o N contido na planta é distribuído por toda a massa. Lembrando também que ao longo do ciclo foram realizadas roçadas com o recolhimento das aparas, ou seja, certa quantidade de nutrientes foi removida com estas.

Foi obtida forte correlação positiva e com altos coeficientes para os ICVs obtidos com o clorofilômetro CM 1000, tanto com as TCSs, que expressam a velocidade de produção do tapete de grama, como a concentração de $\mathrm{N}$ nas folhas da gramabermuda, nas três épocas avaliadas (Tabela 1).

MANGIAFICO \& GUILLARD (2005), utilizando o clorofilômetro CM 1000, verificaram que ele forneceu indicações favoráveis da concentração de clorofila em grama Kentucky bluegrass (Poa pratensis L.) ao longo das estações. Mesmo este aparelho não dispondo de fonte própria de luz,

Tabela 1 - Coeficiente de correlação linear (r) e sua significância entre os índices de reflectância e a concentração de N na lâmina foliar, taxa de cobertura do solo. (TCS)

\begin{tabular}{|c|c|c|c|c|c|c|}
\hline Índices & TCS 89DAC & TCS 124DAC & TCS 161DAC & N 89DAC & N 124DAC & N 161DAC \\
\hline ICV & $0,862^{* *}$ & $0,825^{* *}$ & $0,910^{* *}$ & $0,804^{* *}$ & $0,956^{* *}$ & $0,923^{* *}$ \\
\hline Cor $\mathrm{G}^{1}$ & $-0,279^{\mathrm{NS}}$ & $-0,12^{\mathrm{NS}}$ & $0,08^{\mathrm{NS}}$ & $-0,463^{*}$ & $-0,163^{\mathrm{NS}}$ & $0,057^{\mathrm{NS}}$ \\
\hline Matiz $(\mathrm{H})^{1}$ & $0,849^{* *}$ & $0,778^{* *}$ & $0,926^{* *}$ & $0,757^{* *}$ & $0,832^{* *}$ & $0,923^{* *}$ \\
\hline $\mathrm{ICVE}^{1}$ & $0,808^{* *}$ & $0,744^{* *}$ & $0,901^{* *}$ & $0,772^{* *}$ & $0,829^{* *}$ & $0,943^{* *}$ \\
\hline Cor $\mathrm{G}^{2}$ & $-0,613^{* *}$ & $-0,01^{\mathrm{NS}}$ & $-0,709^{* *}$ & $-0,756^{* *}$ & $-0,450^{*}$ & $-0,792^{*}$ \\
\hline $\operatorname{Matiz}(\mathrm{H})^{2}$ & $0,785^{* *}$ & $0,877^{* *}$ & $0,965^{* *}$ & $0,101^{\mathrm{NS}}$ & $0,843^{* *}$ & $0,902^{* *}$ \\
\hline $\mathrm{ICVE}^{2}$ & $0,834^{* *}$ & $0,882^{* *}$ & $0,964^{* *}$ & $0,530^{*}$ & $0,860^{* *}$ & $0,904^{* *}$ \\
\hline $\mathrm{N}$ & $0,862^{* *}$ & $0,825^{* *}$ & $0,910^{* *}$ & - & - & - \\
\hline
\end{tabular}

ICV - intensidade da cor verde da folha, obtida pelo clorofilômetro CM 1000; cor G, matiz (H) e ICVE (Índice de cor verde escuro da folha); ${ }^{1}$ índices obtidos da análise da imagem digital da grama. ${ }^{2}$ índices obtidos a partir do medidor de cor da grama TCM 500 ao avaliar a grama; *,** e NS significativo a 5, $1 \%$ e não significativo pelo teste $\mathrm{F}$, respectivamente. 
necessitando da luz incidente para ajustar seus valores de leitura, as mudanças de luz nas diferentes estações não influenciaram nas medidas realizadas, pois, devido ao sensor do equipamento, elas foram normalizadas de acordo com a variação da intensidade de luz. MA et al. (1996) verificaram relação positiva da reflectância com o teor de clorofila em plantas de milho. TRENHOLM et al. (1999) obtiveram uma correlação linear positiva entre reflectância e a análise visual em algumas gramíneas. Essa relação pode ser considerada vantagem da utilização de medidores de reflectância em gramas.

$\mathrm{O} \mathrm{G}^{1}$ obtido pela imagem digital não se correlacionou significativamente com a TCS em nenhuma das épocas de avaliação. Houve apenas uma baixa correlação com o N $(-0,463)$ aos 89DAC. Esse mesmo índice, obtido com a utilização do medidor de cor TCM $500\left(\mathrm{G}^{2}\right)$, apresentou correlação com a TCS aos 89 e 161DAC e com a concentração foliar de $\mathrm{N}$ nas três épocas de avaliação, porém os coeficientes de correlação sofreram variações em função das TCSs e da dose de N. A principal diferença entre os valores de RGB obtidos com a análise da imagem digital e com o medidor de cor TCM 500 é que este mede a luz refletida de uma lâmpada artificial isolada da luz solar dentro de uma câmara escura, ficando padronizada a intensidade de luz incidente na folha. Já os valores de RGB obtidos com a análise da imagem de câmera fotográfica digital sofrem influência da intensidade da luz solar, que varia com o decorrer do dia e do ano. Segundo BAESSO et al. (2007), o valor digital do pixel é função do sistema óptico (câmera e lente), da iluminação, da posição relativa planta-sensor-iluminação e das propriedades espectrais da planta. Neste estudo, o sistema óptico e a posição relativa planta-sensor-iluminação para obtenção da imagem digital com a câmera foram controlados; no entanto, a iluminação não foi controlada para tornar a medida mais prática. Para o $\mathrm{H}^{1}$, que é calculado com base nas três cores da imagem digital (RGB), e o ICVE ${ }^{1}$, calculada com base no matiz, saturação e brilho, houve forte correlação positiva com a TCS e com a concentração de $\mathrm{N}$ em grama-bermuda.

Quando foi utilizado o medidor de cor TCM 500 para a obtenção dos valores RGB, o $\mathrm{H}^{2}$ correlacionou-se positivamente com a TCS nas três épocas avaliadas e com a concentração de $\mathrm{N}$ apenas aos 124 e 161DAC. Para o ICVE ${ }^{2}$, as correlações foram significativas, tanto para a TCS, como para a concentração de $\mathrm{N}$ em todas as avaliações.

Dentre os índices utilizados para quantificar a cor verde da grama, obtidos com a utilização do medidor de cor TCM 500, apenas o ICVE correlacionouse com a TCS e com a concentração de $\mathrm{N}$ em todas as épocas amostradas. Dos índices obtidos da análise da imagem digital, tem-se que o $\mathrm{H}$ da cor verde da imagem da grama e o ICVE proporcionaram correlações moderadas a fortes com a TCS e com o N. Dessa forma, a obtenção de índices de cor verde pela análise da imagem digital, embora mais trabalhosa, foi mais eficiente que o medidor de cor TCM 500 para gramabermuda, possivelmente pela maior área de avaliação (cerca de $2 \mathrm{~m}^{2}$ ), quando comparada com os demais métodos. Com a utilização de palmtop com câmera digital integrada de resolução superior a 3 megapixels, as imagens poderão ser obtidas e processadas no campo, agilizando o processo de obtenção de índices a partir da imagem digital. O clorofilômetro CM 1000, além de proporcionar medidas instantâneas, que podem ser realizadas no campo, proporcionou as maiores correlações com a concentração de N na lâmina foliar. Segundo MANGIAFICO \& GUILLARD (2005), os dados obtidos por esse medidor de refletância podem ser utilizados para auxiliar no manejo de $\mathrm{N}$ em gramados. Uma das dificuldades da utilização do clorofilômetro CM 1000 refere-se à aquisição do aparelho, que somente depende de importação, podendo ser mais vantajosa a utilização de imagem digital. Os índices obtidos a partir da imagem digital, embora requeiram um método mais trabalhoso e não instantâneo, demandam equipamentos de mais fácil aquisição e menor custo.

A partir de uma área de referência que recebeu adubação nitrogenada em dose superior à necessária para a formação de tapetes de grama-bermuda de qualidade, os valores obtidos nesta área passam a ser referência para os índices de cor verde, visto que as equações geradas em função das doses de $\mathrm{N}$ demonstram que esses valores não aumentam a partir de um valor limite. Esses índices podem ser bons indicadores do momento de aplicação do adubo nitrogenado, com a finalidade de aumentar a eficiência de utilização do N aplicado. Quando os índices da área a ser adubada já se encontram próximos aos valores de referência, a adubação poderá ser atrasada, ou até mesmo cancelada. Estudos futuros, entretanto, são necessários para determinar a viabilidade dos métodos, bem como a aplicabilidade de medidas desses índices em várias espécies de grama, condições ambientais e de manejo.

\section{CONCLUSÃO}

O H e o ICVE, obtidos de imagem digital, o ICVE, obtido com o medidor de cor TCM 500, e a ICV, obtida com o clorofilômetro CM 1000, apresentam correlação positiva com a concentração de N e a TCS de grama-bermuda, podendo ser utilizados como ferramenta para auxiliar a recomendação da adubação nitrogenada para a cultura. 


\section{REFERÊNCIAS}

BACKES, C. et al. Estado nutricional em nitrogênio da grama esmeralda avaliado por meio do teor foliar, clorofilômetro e imagem digital, em área adubada com lodo de esgoto. Bragantia, v.69, n.3, p.661-668, 2010. Disponível em: <http:/ /www.scielo.br/scielo.php?script=sci_arttext\&lng=pt\&nrm =iso\&tlng=pt\&pid=S0006-87052010000200021 $>$. Acesso em: 24 nov. 2010. doi: 10.1590/S0006-87052010000200021.

BAESSO, M.M. et al. Determinação do "status” nutricional de nitrogênio no feijoeiro utilizando imagens digitais coloridas. Engenharia Agrícola, v.27, n.2, p.520-528, 2007. Disponível em: $<$ http://www.scielo.br/scielo.php?pid=S0100-69162007000300022\& script=sci_arttext>. Acesso em: 10 de nov. 2010. doi: 10.1590/ S0100-69162007000300022.

BOWMAN, D.C. et al. Fate and transport of nitrogen applied to six warm-season turfgrasses. Crop Science, v.42, p.833841, 2002. Disponível em: <https://www.crops.org/publications/ cs/articles/42/3/833>. Acesso em: 02 dez. 2009. doi: 10.2135/ cropsci2001.8330.

CARROW, R.N. et al. Turfgrass soil fertility and chemical problem: assessment and management. Chelsea, MI: Ann Arbor, 2001. 400p.

EMBRAPA. Centro Nacional de Pesquisa de Solos-CNPS. Sistema brasileiro de classificação de solos. Brasília: Embrapa-SPI; Rio de Janeiro: Embrapa-CNPS, 2006. 306p.

FERREIRA, D.F. Análises estatísticas por meio do Sisvar para Windows versão 4.0. In: REUNIÃO ANUAL DA REGIÃO BRASILEIRA DA SOCIEDADE INTERNACIONAL DE BIOMETRIA, 45., 2000, São Carlos, SP. Anais... São Carlos: UFSCar, 2000. p.255-258.

CHRISTIANS, N.E. Fundamental of turfgrass management. 4.ed. Chelsea, MI: Arbor, 2011. 424p.

EASTON, Z.M.; PETROVIC, A.M. Fertilizer source effect on ground and surface water quality in drainage from turfgrass. Journal of Environmental Quality, v.33, p.645-655, 2004. Disponível em: <https://www.soils.org/publications/jeq/articles/ 33/2/645>. Acesso em: 06 dez. 2009. doi: 10.2134/ jeq2004.6450.
GODINHO, M.S. et al. Classificação de refrigerantes através de análise de imagens e análise de componentes principais (PCA). Química Nova, v.31, n.6, p.1485-1489, 2008. Disponível em: $<$ http://www.scielo.br/scielo.php?script=sci_arttext\&pid=S010040422008000600039>. Acesso em: 3 out. 2010. doi: 10.1590/ S0100-40422008000600039.

GODOY, L.J.G. Adubação nitrogenada para produção de tapetes de grama Santo Agostinho e esmeralda. 2005. 106f. Tese (Doutorado em Agronomia/Agricultura) - Botucatu, Universidade Estadual de São Paulo, SP.

KARCHER, D.E; RICHARDSON, M.D. Quantifying turfgrass color using digital image analysis. Crop Science, v.43, p.943951, 2003. Disponível em: <https://www.crops.org/publications/ cs/articles/43/3/943>. Acesso em: 24 jul. 2009. doi: 10.2135/ cropsci2003.9430.

MA, B.L. et al. Canopy light reflec tance and field greenness to assess nitrogen fertilization and yield of maize. Agronomy Journal, v.88, p.915-920, 1996. Disponível em: <https://www.crops.org/publications/ aj/abstracts/88/6/AJ0880060915?access=0\&view=pdf $>$. Acesso em: 20 jul. 2009.

MALAVOLTA, E. et al. Avaliação do estado nutricional das plantas: princípios e aplicações. 2.ed. Piracicaba: POTAFOS (Associação brasileira de pesquisa da potassa e do fosfato), 1997. 317p.

MANGIAFICO, S.S; GUILLARD, K. Turfgrass reflectance measurements, chlorophyll, and soil nitrate desorbed from anion exchange membranes. Crop Science, v.45, p.259-265, 2005. Disponível em: <https://www.agronomy.org/publications/cs/ articles/45/1/0259>. Acesso em: 24 jul. 2009. doi: 10.2135/ cropsci2005.0259.

SYSTAT SOFTWARE INC. SigmaStat. Versão: 3.1 for Windows. Point Richmond, CA.: INSO Corporation, 2004. 848p.

TRENHOLM, L.E. et al. Relationship of multispectral radiometry data to qualitative data in turfgrass research. Crop Science, v.39, p.763-769, 1999. Disponível em: <https:// www.crops.org/publications/cs/abstracts/39/3/ CS0390030763? access=0\&view=pdf $>$. Acesso em: 13 abr. 2009. 